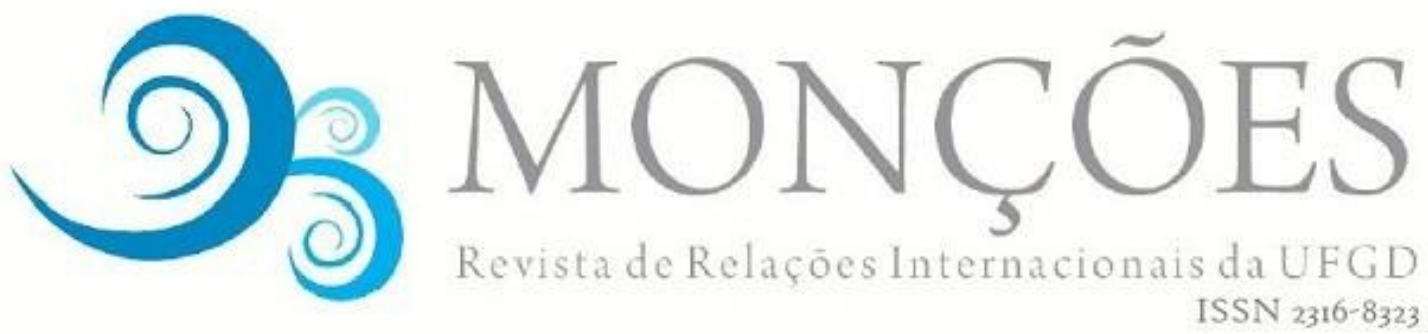

\title{
LÓGICAS DE PREVENÇÃO, LEGIBILIDADE E INTERVENÇÃO: COMPOSIÇÕES CARTOGRÁFICAS SOBRE O "CRIME" NO POLICIAMENTO PREDITIVO E NA GESTÃO DE CRISES INTERNACIONAIS
}

\author{
LUÍSA CRUZ LOBATO \\ Pontifícia Universidade Católica do Rio de Janeiro (PUC-Rio), Instituto de Relações \\ Internacionais, Rio de Janeiro - RJ, Brasil. \\ ORCiD: 0000-0003-2192-6243 \\ I.cruzlobato@gmail.com
}

VICTÓRIA MONTEIRO DA SILVA SANTOS

Pontifícia Universidade Católica do Rio de Janeiro (PUC-Rio), Instituto de Relações Internacionais, Rio de Janeiro - RJ, Brasil. ORCiD: 0000-0003-0282-8226 victoria.mssantos@gmail.com

\begin{abstract}
Resumo: O presente artigo contrasta duas lógicas distintas de prevenção que participam na governança contemporânea do crime: o policiamento preditivo e a gestão de crises internacionais. Mostramos como, nos dois casos analisados, o "crime" é tornado legível enquanto problema, possibilitando formas distintas de intervenção, a partir da realocação da presença policial no caso do policiamento preditivo, e da difusão de modelos de boa governança no caso da gestão de crises internacionais. llustramos como ambos os processos dependem da construção autoritativa de cartografias de risco para informar a adoção de tais modos de intervenção em nome da gestão do "crime". Nessas cartografias, a distribuição espacial do risco se funda, por um lado, na autoridade do conhecimento estatístico, e, por outro lado, na presença do especialista no "campo". As formas de intervenção prescritas nesses contextos, por sua vez, reproduzem uma leitura gerencialista da prevenção do fenômeno criminal, que prioriza intervenções focadas na gestão do crime enquanto uma conjunção de riscos, relegando ao segundo plano elementos estruturais que contribuem para sua existência e circunscrevendo, assim, a sua política à gestão de crises e eventos.
\end{abstract}

Palavras-Chave: Governança do crime; Policiamento preditivo; Gestão de crises internacionais.

\section{LOGICS OF PREVENTION, LEGIBILITY AND INTERVENTION: CARTOGRAPHICAL COMPOSITIONS OF "CRIME" IN PREDICTIVE POLICING AND IN INTERNATIONAL CRISIS MANAGEMENT}

Abstract: This article contrasts two different logics of prevention that participate in contemporary crime governance: predictive policing and international crisis management. We demonstrate how, in the two cases analyzed here, "crime" is made legible as a problem, enabling different forms of intervention, based on the relocation of the police presence in the case of predictive policing, and on the diffusion of models of good governance in the case of international crisis management. We illustrate how both processes rely on the authoritative construction of risk cartographies to inform the adoption of such modes of intervention in the name of crime management. In these cartographies, the spatial distribution of risk is based, on the one hand, on the authority of statistical knowledge, and, on the other hand, on the 
presence of crisis experts in the "field". The forms of intervention prescribed in these contexts, in turn, reproduce a managerial reading of crime prevention, which prioritizes interventions focused on the management of crime as a conjunction of risks, relegating to the background structural elements that contribute to its existence and circumscribing, thus, its policy to the management of crises and events.

Keywords: Crime governance; Predictive policing; International crisis management.

\section{LÓGICAS DE PREVENCIÓN, LEGIBILIDAD E INTERVENCIÓN: COMPOSICIONES CARTOGRÁFICAS SOBRE EL "CRIMEN" EN LA POLICÍA PREDICTIVA Y EN LA GESTIÓN DE CRISIS INTERNACIONALES}

Resumen: Este artículo contrasta dos lógicas de prevención distintas que participan en la gobernanza contemporánea del crimen: la policía predictiva y la gestión de crisis internacionales. Mostramos cómo, en los dos casos analizados, el "crimen" se hace legible como problema, posibilitando diferentes formas de intervención, basadas en la reubicación de la presencia policial en el caso de la policía predictiva, y en la difusión de modelos de buena gobernanza en el caso de la gestión de crisis internacionales. Ilustramos cómo ambos procesos dependen de la construcción autoritativa de cartografías del riesgo para informar la adopción de tales modos de intervención en nombre de la gestión del "crimen". En estas cartografías, la distribución espacial del riesgo se basa, por un lado, en la autoridad del conocimiento estadístico y, por otro, en la presencia del especialista en el "campo". Las formas de intervención prescritas en estos contextos, a su vez, reproducen una lectura gerencialista de la prevención del fenómeno criminal, que prioriza las intervenciones enfocadas en la gestión del crimen como conjunción de riesgos, relegando a un segundo plano elementos estructurales que contribuyen a su existencia y circunscribiendo, así, su política a la gestión de crisis y eventos.

Palabras-Clave: Gobernanza del crimen; Policía predictiva; Gestión de crisis internacionales.

\section{Introdução ${ }^{1}$}

A ideia de "prevenção do crime" se faz presente de inúmeras formas em diferentes esferas de governança, da associação de moradores de um bairro a recomendações de organismos intergovernamentais. Duas formas por meio das quais essa ideia se expressa são de particular interesse neste artigo. No nível das corporações policiais subnacionais, o "policiamento preditivo" propõe lidar com o crime a partir da alocação de efetivos policiais para áreas da cidade com alta probabilidade de ocorrência desses eventos. Já no nível das esferas de governança global, o "crime" tem emergido enquanto problema que se coloca para os mecanismos de gestão de "crises internacionais".

\footnotetext{
${ }^{1} \mathrm{O}$ presente trabalho foi realizado com apoio da Fundação de Amparo à Pesquisa do Estado do Rio de Janeiro (FAPERJ) e da Coordenação de Aperfeiçoamento de Pessoal de Nível Superior - Brasil (CAPES) - Código de Financiamento 001.
} 
A escolha destas duas lógicas de prevenção visa destacar as conexões entre esferas usualmente entendidas como distintas, especialmente com relação à produção da ordem. Afinal, enquanto no espaço urbano a presença policial é usualmente presumida como expressão de uma autoridade centralizada, no âmbito internacional, o tropo da "anarquia" parece deslocar as possibilidades de um policiamento da "desordem".

De modo geral, a prevenção pode ser entendida como uma composição de ideias sobre a capacidade de predizer e de intervir (FREEMAN, 1999). No cerne desta ideia está a capacidade de produzir conhecimento sobre os riscos, entendidos por Aradau e van Munster (2007, p.91) enquanto dispositivos (dispositifs) para governar problemas sociais. Para os autores, tais dispositivos formam assemblages heterogêneas, compostas por elementos discursivos e materiais. Esta conceituação nos importa por duas razões: primeiramente, por chamar a atenção para a natureza contingente daquilo que é expressado enquanto prevenção. Em segundo lugar, por nos permitir atentar para as práticas e conhecimentos que sustentam a prevenção.

Uma destas práticas é a cartografia, isto é, a produção de 'mapas', a partir de um conjunto de conhecimentos científicos, técnicos ou artísticos, visando expressar ou representar objetos, ambientes ou fenômenos. Entendemos a cartografia enquanto técnica que exerce um duplo papel: por um lado, possibilita conhecer e representar o fenômeno criminal; por outro lado, autoriza formas específicas de intervenção, visando evitar ou mitigar tal risco.

Compreender as composições cartográficas em torno da prevenção do crime a partir do policiamento preditivo e da gestão de crises internacionais nos possibilita refletir sobre o modo como práticas contemporâneas de produção da (in)segurança são pensadas, reforçadas e justificadas. Participam dessas práticas uma série de tecnologias e modos de conhecer/entender o fenômeno criminal, inspiradas por um modelo de governança gerencialista, a partir do qual o fenômeno 'crime' ganha conotação de risco, ou seja, um evento futuro, com consequências potencialmente negativas, que gera um imperativo de ação presente para ser evitado. Essa ação envolve uma cuidadosa consideração de fatores que explicam ou contribuem para um determinado cenário de risco, que se sabe que pode ser mitigado, porém raramente 
superado. Uma vez que o fenômeno criminal passa a ser retratado como gerenciável, a ação visando evitar ou mitigar sua incidência se transforma significativamente: tornase possível gerenciá-lo em seus aspectos mais 'micro', a exemplo da modulação de comportamentos "desejáveis" e da gestão de elementos que des/favorecem a incidência do crime, e macro, como o desenho de instituições e estruturas para 'governá-lo'.

No cerne do nosso argumento está a constatação de que, embora a prevenção adquira diferentes formas, há um padrão a ser identificado em sua aplicação enquanto prevenção do crime. Esse padrão se traduz em uma leitura gerencialista do fenômeno criminal que relega ao segundo plano elementos estruturais que contribuem para sua existência, como, por exemplo, o modo como a desigualdade social integra a equação que explica a prática de certos tipos criminais. Além disso, limita-se o espaço de disputas políticas acerca das concepções particulares de "risco" e "ordem" que informam tais esforços de gestão, a partir da mobilização de formas específicas de expertise que somente autorizam determinados diagnósticos e soluções para o problema do "crime".

Ao mesmo tempo, a produção de representações cartográficas oferece a possibilidade de imaginar risco, ordem e desordem a partir de outras perspectivas para além daquelas dominantes. Desse modo, compreendemos a cartografia enquanto prática híbrida, contingente e complexa e argumentamos por sua relevância enquanto 'espaço' de disputa em torno da produção da (in)segurança.

O artigo está assim estruturado: primeiramente, apresentamos e discutimos as práticas do policiamento preditivo e gestão de crises internacionais, destacando sua inserção em uma concepção gerencial da produção da ordem. Em seguida, discutimos as formas como tais lógicas tornam o crime legível enquanto problema enquanto um padrão espacializado de comportamento em diferentes áreas de uma cidade no primeiro contexto e enquanto o centro de uma crise a ser gerenciada pela comunidade internacional no segundo - , a partir da mobilização de formas distintas de expertise e da produção de representações cartográficas baseadas nestas. Logo, exploramos as formas como tais leituras do fenômeno criminal tornam possíveis intervenções baseadas na realocação da presença policial no espaço, no primeiro 
caso, e nas prescrições de formas de "boa governança", no segundo. Finalmente, discutimos algumas das formas como expertise e intervenção se constituem mutuamente na produção de concepções específicas da ordem, redesenhando o espaço das disputas políticas.

\section{Lógicas de prevenção na governança do "crime"}

"É melhor prevenir do que remediar": esta premissa está no centro da arquitetura intelectual da modernidade, sendo incorporada às mais diversas práticas. $\mathrm{O}$ caráter normativo da "prevenção" enquanto projeto se expressa na distinção entre o desejável e o indesejável, este último enquanto conjunto de práticas que se pretende eliminar a partir de esforços de engenharia social. Como expresso no dito popular, a "prevenção" dificilmente gera discordâncias explícitas, embora intervenções específicas autorizadas em seu nome sejam sempre objeto de disputas políticas, além de ser frequentemente tida como mais barata e eficiente do que o remédio (FREEMAN, 1999, p.234-235).

$\mathrm{Na}$ segurança pública, políticas de prevenção do crime receberam atenção crescente nas últimas décadas, sendo geralmente apresentadas em oposição a uma abordagem centralizada no sistema de justiça penal. Como princípio, porém, a prevenção sempre esteve ao centro das políticas de justiça criminal na modernidade, sendo a própria institucionalização da polícia (como corpo permanente) e da prisão frequentemente justificadas com referência à prevenção de determinados comportamentos ou de sua reincidência.

A multiplicidade de políticas associadas ao rótulo da prevenção se refletiu no desenvolvimento de diversas tipologias - como aquela que, emprestando termos da literatura sobre epidemiologia médica, distingue entre a prevenção primária (que atua sobre o público ou ambiente geral), secundária (que atua especificamente sobre aqueles que estão "em risco" de cometer ou sofrer um crime), e terciária (que se volta para aqueles que já cometeram ou sofreram um crime) ${ }^{2}$ (GILLING, 1997, p.1-4).

2 Outra categorização distingue a "prevenção situacional do crime", focada na gestão do ambiente físico de forma a reduzir as oportunidades para a ação criminal, e a "prevenção social do 303 
Assim, a ideia de prevenção criminal é empregada em políticas públicas tão distintas quanto mudanças no espaço público, incluindo sua ocupação e iluminação, além da reabilitação de presos visando evitar reincidência (LAB, 2010).

Em meio à categoria da prevenção "secundária", encontram-se os esforços de predizer onde e quando crimes vão ocorrer, de modo a alocar a presença policial de forma mais "eficiente". Esse tipo de lógica preventiva se situa no contexto de transformações amplas nas práticas de policiamento, que ganham corpo no início da década de 1990 em departamentos de polícia na Europa e Estados Unidos e dizem respeito à convergência entre departamentos de polícia e setor privado, mediante a incorporação de práticas gerenciais ao trabalho policial, como a avaliação de performance e resultados do trabalho policial, e de ferramentas e técnicas de gestão criminal no cotidiano do policiamento (JONES; NEWBURN, 2002; O'MALLEY; HUTCHINSON, 2007; TERPSTRA; TROMMEL, 2009; WHITE; GILL, 2012). No Brasil, esse crescente gerencialismo pode ser associado a estratégias mais amplas de legitimação do trabalho policial (BATITUCCI, 2019).

De acordo com o dicionário SAGE de policiamento, o gerencialismo se divide em duas correntes. A primeira faz forte ênfase às demandas do "consumidor" e diz respeito à importação de métodos de gerenciamento do setor privado para o setor público, a exemplo da gestão de resultados e recursos ("fazer mais com menos"). Já a segunda se refere ao processo de "marketização", iniciado ainda na década de 1970 com a introdução de estruturas de incentivos (p.ex., competição de mercado e mecanismos de preço) na provisão do serviço público, a fim de aumentar sua eficiência (WAKEFIELD; FLEMING, 2020; BEVIR, 2009). Mais amplamente, o processo gerencial enfatiza a desagregação das burocracias estatais, a elaboração de planos de negócios, a terceirização e a subcontratação de serviços.

A introdução das tecnologias da informação e comunicação (TICs) ao cotidiano policial vem diretamente ao auxílio desse processo de reestruturação das atividades dos departamentos de polícia. Em particular, a reorientação do trabalho policial para um futuro populado por dados e a adoção de ferramentas tecnológicas ajudaram a

crime", que se volta para transformações no ambiente social com o objetivo de mudar motivações criminais, como políticas de educação e geração de empregos (GILLING, 1997, p.3-4).

304 
compor um cenário onde práticas digitais de gestão e condução do policiamento são amplamente difundidas (KAUFMANN; EGBERT; LEESE, 2018). Essas práticas incluem, por exemplo, o desenvolvimento de sistemas para registro de ocorrências e despachos, policiamento por manchas de calor para alocação de efetivo, softwares de gestão de policiamento e o policiamento preditivo.

A possibilidade de "prever" onde um crime vai acontecer e a premissa de otimização de recursos que a acompanha têm se mostrado atrativas para departamentos de polícia pressionados por cortes orçamentários e de pessoal, apesar da árdua e complicada realidade de se colocar grandes sistemas de análise de dados para funcionar (KITCHIN, 2014; MAGUIRE; MCVIE, 2017). Por trás da ampla difusão dessa tecnologia de policiamento, estão grandes narrativas sobre o potencial do big data e mineração de dados para o trabalho policial, além de pressupostos sobre como a informatização dos departamentos de polícia os capacita para processar quantidades sem precedentes de dados e para colocar em prática análises suportadas por algoritmos (KAUFMANN; EGBERT; LEESE, 2018).

A premissa de se prever um crime não é nova. Há décadas, modelos estatísticos e matemáticos são usados para indicar onde um crime poderá acontecer, gerenciar a concentração de crimes no espaço e estimar a probabilidade de um certo tipo criminal prevalecer em um dado momento e área da cidade (HACKING, 1990).

Na prática, muito do policiamento preditivo contemporâneo se ampara na análise da probabilidade de um crime ou grupo de crimes acontecerem em uma dada porção do espaço (AGUIRRE; BADRAN; MUGGAH, 2019; DULCE; RAMÍREZ-AMAYA; RIASCOS, 2018; KAUFMANN; EGBERT; LEESE, 2018; FLORES ARIAS, 2014), muito embora haja um número mais modesto de abordagens cuja predição é focada nos indivíduos ${ }^{3}$ (DEVIA; WEBER, 2013). A análise espacial depende do processamento de dados históricos sobre as ocorrências em um determinado local e de dados relativos às suas características - por exemplo, se é rodovia ou rua, se

\footnotetext{
3 Essa antecipação tem lugar no nível do tipo criminal enquanto um "agregado" no lugar de individualmente. Desse modo, cenários de ficção científica como os imaginados em filmes como Minority Report - o principal tropo utilizado para se falar de policiamento preditivo - estão longe de serem concretizados: não se antecipa um crime a ser cometido por um indivíduo, somente a chance de um tipo criminal ocorrer.
}

305 
possui iluminação pública ou que tipo de estabelecimentos comerciais há na área). Esse agregado de dados, por sua vez, serve de base para a produção de estimativas - empreendidas por algoritmos de aprendizado de máquina - sobre a probabilidade de um ou mais tipos criminais tornar a ocorrer no local, considerados diversos fatores de risco, como os elencados acima, e condições ambientais, como dia da semana, horário do dia e, algumas vezes, até mesmo a previsão do tempo.

No contexto das práticas de policiamento contemporâneas, a predição de crimes desloca a necessidade de descrever padrões criminais para aquela de predizê-los e antecipá-los (MUGGAH, 2016). Ao fazer isso, alegadamente contribui para uma melhoria na gestão dos recursos policiais e na decisão sobre como e onde alocá-los. De modo mais amplo, faz parte de uma lógica de policiamento baseada no risco, que coloca ênfase na coleta, compilação, análise, cálculo, comunicação da informação dentro dos departamentos de polícia, aliando-se bem a práticas de análise de dados que hoje se popularizam nesses espaços. De acordo com Gundhus (2005), isso muda o foco do policiamento da investigação reativa de crimes específicos para uma abordagem direcionada e orientada para o futuro.

Cabe ressaltar que, mais do que informar quando e onde um crime acontecerá e possibilitar o controle de sua ocorrência prática, o policiamento preditivo avança a necessidade de gestão das ocorrências criminais, ou seja, de decisões relativas aos contextos nos quais certos crimes devem ser dissuadidos mediante a presença policial. Com isso, traz uma forma de antecipação que tem por implicação decisões sobre onde, quando e como intervir (AGUIRRE; BADRAN; MUGGAH, 2019; MUGGAH, 2016).

A prevenção, nesse sentido, é seletiva, visto que, diante das severas limitações dos departamentos de polícia, não é possível agir sobre todas as predições criminais fornecidas pelo sistema, e tem dois momentos: primeiramente, gera-se uma expectativa de ação por parte do comando do batalhão - p.ex., o sistema diz que as áreas $\mathrm{A}, \mathrm{B}$ e $\mathrm{X}$ da cidade concentram o maior número de roubos a pedestres. $\mathrm{O}$ segundo momento é onde a prevenção se "efetiva", quando, motivado pela predição do sistema, o comando opta por priorizar a região $\mathrm{X}$, por ser onde se evidencia um maior fluxo de turistas, e, devido à presença policial, o evento previsto não ocorre. $\mathrm{Na}$ 
prática, pode ser difícil afirmar que o crime deixou de acontecer por causa da presença policial, mas para efeitos do sucesso da lógica de prevenção, a correlação entre presença policial guiada pelo sistema e a não ocorrência do evento bastam.

Esta particularidade do policiamento preditivo implica um modo de prevenção não mais baseado apenas na necessidade de evitar que o evento aconteça, mas também na necessidade de demonstrar a capacidade de resposta aos padrões criminais identificados. Em outras palavras: a prevenção se articula em torno da possibilidade de o evento acontecer e da capacidade de ação sobre aquele evento (Amoore, 2013, p.62). Por sua vez, práticas de cálculo se tornam úteis na medida em que diferentes entidades (dados sobre comportamentos de indivíduos, disposição das coisas no espaço, meteorologia ou eventos passados, por exemplo) podem ser arranjadas e rearranjadas de modo a especular sobre aquilo que está ausente ou incerto (AMOORE, 2013; CALLON; MUNIESA, 2005).

Em contrapartida, quando olhamos para o âmbito da governança internacional, a ênfase na prevenção tende a remeter às crises e conflitos internacionais, e em geral se conecta à demanda pela criação de sistemas de "alerta prévio" que permitam identificar potenciais crises em seus estágios iniciais. Aqui, a ideia de gestão de crises internacionais conduz à emergência de uma lógica de prevenção que se reflete na produção de relatórios diagnosticando tais crises em potencial e prescrevendo políticas e transformações institucionais que permitam transformar suas causas.

No contexto da Organização das Nações Unidas (ONU), essa dupla demanda por sistemas de alerta prévio e pelo foco na prevenção - está presente em sucessivas análises internas do papel da organização na paz e segurança internacionais, como ilustrado pelo relatório An Agenda for Peace: Preventive Diplomacy, Peacemaking and Peaceeeping (1992) lançado pelo então Secretário-Geral Boutros Boutros-Ghali (ZENKO; FRIEDMAN, 2011). Em particular, a ideia de desenvolver sistemas de alerta prévio para crises políticas e/ou conflitos armados ganhou visibilidade nos fóruns multilaterais internacionais desde a década de 1990, embora houvesse debates anteriores sobre essas práticas nas décadas de 1970 e 1980 (NYHEIM, 2009). A centralidade da prevenção como abordagem à produção da ordem internacional foi reforçada no relatório publicado em 2001 pela Comissão Internacional sobre 
Intervenção e Soberania Estatal (sigla em inglês: ICISS), no qual se estabeleceu o conceito de Responsabilidade de Proteger (R2P). Segundo o relatório, a responsabilidade dos Estados e da comunidade internacional pela proteção de civis abrange três elementos: prevenção - apresentada como "a dimensão mais importante da responsabilidade de proteger" -, reação e reconstrução (ICISS, 2001, p. XI).

Aqui, ganha centralidade a produção de análises que buscam identificar contextos em que atrocidades em massa podem ocorrer, de maneira a tornar possível a ação internacional preventiva. Os produtos dessas práticas de alerta prévio, geralmente empreendidas por organizações multilaterais, iniciativas da sociedade civil ou agências governamentais, são apresentados em formas como relatórios ou índices globais, incluindo aqueles que classificam os estados de acordo com sua "fragilidade" ou com os impactos do terrorismo (INSTITUTE FOR ECONOMIC AND PEACE, 2018), funcionando como listas que "ajudam as agências que trabalham nessas questões a estabelecer prioridades" (NYHEIM, 2009, p. 14).

Uma organização da sociedade civil com crescente proeminência no campo das práticas de alerta prévio de conflitos e crises internacionais é o International Crisis Group (ICG). De acordo com a "missão" apresentada em seu site,

Crisis Group soa o alarme para prevenir conflitos letais. Promovemos o apoio à boa governança e políticas inclusivas que permitem que as sociedades prosperem. Nós nos envolvemos diretamente com uma variedade de atores dos conflitos para buscar e compartilhar informações e encorajar ações inteligentes pela paz (ICG, [s.d. a]).

Segundo a narrativa histórica apresentada em seu site, o ICG foi fundado em 1995 "por um grupo de estadistas proeminentes que se desesperaram com o fracasso da comunidade internacional em antecipar e responder efetivamente às tragédias da Somália, Ruanda e Bósnia" (ICG, [s.d.b]) De fato, a presença de "estadistas proeminentes", não apenas no grupo fundador, mas também no atual conselho diretivo, é reivindicada como essencial para o potencial impacto da organização em termos de prevenção de atrocidades, pois essas pessoas estariam em uma posição privilegiada para conectar o conhecimento coletado em campo às mais altas esferas da tomada de decisões. 
Para Bliesemann de Guevara (2014), o ICG se apresenta como um ator central no campo de expertise sobre crises e conflitos internacionais devido ao emprego de uma metodologia específica que conjuga três elementos: a produção de pesquisas precisas e temporalmente oportunas por seus experts, a partir da sua extensa presença em campo; a utilidade prática de suas prescrições políticas; e a influência de alto-nível sobre os formuladores de políticas públicas internacionais. A partir do emprego dessa metodologia, o ICG produz relatórios, listas, e vídeos que representam determinadas situações como "crises internacionais", ou seja, como perturbações excepcionais que colocam em risco a segurança de determinadas populações, demandando respostas urgentes para a prevenção de atrocidades. Um dos principais produtos através dos quais a organização oferece seu diagnóstico acerca das "crises" contemporâneas é o Crisis Watch, que será discutido na próxima seção.

De modo geral, as "crises" monitoradas e relatadas pela organização são aquelas comumente entendidas como "políticas", como no caso de conflitos armados interestatais ou intraestatais, ou tensões políticas internacionais. No contexto latinoamericano, contudo, questões relacionadas ao crime organizado ganham centralidade crescente na identificação de "crises" de segurança. Assim, em 2005, o conflito armado e o comércio ilegal de drogas na Colômbia foram descritos em um relatório do ICG como "pragas gêmeas", e as interconexões entre violência política e narcotráfico foram exploradas em diversos documentos da organização desde então. Em 2013, porém, a questão do narcotráfico ganhou centralidade ainda maior a partir da inclusão do México como um contexto de "crise" a ser monitorado, a despeito da ausência de um conflito armado formalmente reconhecido. Em relatório daquele ano, o Estado mexicano era identificado como institucionalmente débil face à "crise de segurança" enfrentada no país (HOCHMÜLLER; MÜLLER, 2014). Desde então, como será discutido nas próximas seções, a continuidade do monitoramento do contexto mexicano pelo ICG teve implicações importantes tanto em termos de como o crime organizado é tornado legível enquanto crise internacional quanto com relação às formas de intervenção prescritas pela organização.

Ao longo desta seção foram apresentadas duas lógicas por meio das quais a ideia de "prevenção do crime" se expressa: por um lado, a lógica do policiamento 
preditivo, pautada pela identificação de zonas urbanas marcadas por um maior risco de ocorrências criminais; e por outro, a lógica da gestão de crises internacionais, que mais recentemente passa a incluir o "crime" enquanto risco a ser gerido por tomadores de decisão internacionais. Em ambos os contextos, a criminalidade emerge como problema concebido em termos gerenciais, e a prioridade da prevenção é justificada em termos de uma eficiência em administrar sua incidência. Nas próximas seções, serão exploradas as formas como essas duas lógicas tornam o fenômeno criminal legível enquanto risco a ser administrado e autorizam formas de intervenção profundamente gerencialistas em nome de sua gestão.

\section{Tornando o "crime" legível: composição cartográfica do risco e governança preventiva}

Atentamos agora para o modo como crime é tornado legível a partir do modo como o saber matemático-estatístico, no caso do policiamento preditivo, e o conhecimento produzido a partir "do campo", no sistema de alerta prévio do ICG, são mobilizados de modo a representar o fenômeno criminal — representações essas que autorizam intervenções específicas, a exemplo do controle do crime a partir da presença policial ou do combate a "causas-raiz" de um conflito mediante programas de cooperação para o desenvolvimento, assistência técnica, etc., com o intuito de gerenciá-lo.

Uma distinção se torna importante se queremos entender estas composições cartográficas: aquela entre predizer e explicar. Essa distinção ilustra como, muito embora a ideia de prevenção se oriente para o futuro, diferentes lógicas de prevenção estabelecem relações distintas entre o futuro que se pretende modificar e aquilo que se observa no presente e no passado.

A distinção entre predição e explicação se centra em dois elementos: relações de causa e efeito e o modo como o passado sustenta a predição. Por um lado, o esforço explicativo busca identificar relações de causa e efeito entre certas variáveis, possuindo uma orientação forte para o passado, onde localizam-se as causas. Isso se alinha com o modo como, em certos campos do conhecimento, entende-se que a identificação de relações de causa e efeito com maior grau de certeza 
(frequentemente entendidas como "leis naturais") possibilita maior conhecimento preditivo (ver RESCHER, 1958). Retornaremos a este ponto adiante.

Por outro lado, o esforço preditivo se baseia em agregados de eventos passados para estimar o comportamento de uma variável em observações futuras (CHADEFAUX, 2017). A ascensão do pensamento estatístico no século XIX transformou o modo como hoje percebemos o fenômeno criminal, estando na base de nossa obsessão por mensurá-lo (HACKING, 1990).

No contexto da atual tendência de digitalização do policiamento, a identificação de regularidades em fenômenos criminais ${ }^{4}$ ganha novos contornos, somando-se, por um lado, à proliferação de dispositivos móveis, redes sociais e sensores capazes de captar um grande volume de 'pequenas' informações sobre o comportamento das pessoas e características do ambiente à sua volta e, por outro lado, a modelos matemáticos utilizados para gerar generalizações e predições a partir dessas informações.

A autoridade estatística parte do pressuposto de que é relevante identificar padrões (ou sua ausência) em um conjunto vasto de dados (HACKING, 1990). ${ }^{5}$ Além disso, outros pressupostos são necessários para tornar o crime legível e, portanto, passível de ser algoritmicamente previsto. Primeiro: deve-se considerar que certos tipos de crime se concentram no espaço. Diretamente relacionado, está o pressuposto de que alguns tipos de crimes têm maior probabilidade de acontecer em certos dias e horários da semana do que outros. Segundo: é necessário que os dados utilizados na predição sejam "limpos" e de boa qualidade, ou seja, que não haja informações faltando (p.ex., subnotificações em excesso), preenchimento/tratamento incorreto de dados (p.ex., duplicação), que o georreferenciamento seja o mais preciso possível, etc. Terceiro: o crime é, de modo mais geral, compreendido em termos de um cálculo

\footnotetext{
${ }^{4}$ Essa prática é possível apenas a partir do momento em que tais eventos passaram a ser registrados, categorizados e quantificados em larga escala, situando-se no contexto de esforços amplos de se governar populações e construir poder nacional. Ver: Hacking (1990).

${ }^{5}$ Nas Relações Internacionais, por exemplo, há amplo debate sobre o uso de métodos estatísticos para compreender padrões em um número grande de observações (MCALLISTER; LABROSSE, 2014; MEARSHEIMER; WALT, 2013; SPRINZ; WOLINSKY-NAHMIAS, 2004). O método estatístico serve, aqui, de mecanismo de validação que tanto proporciona uma visão ampla sobre um universo ' $n$ ' de casos, como permite identificar padrões que, quando confrontados com premissas teóricas basilares das disciplina, poderão suportá-las ou refutá-las segundo a lógica de que uma boa teoria se relaciona a padrões presentes em uma quantidade relevante de casos (MCALLISTER; LABROSSE, 2014).
} 
racional. Quarto: o crime se espalha de um local a outro da mesma forma que uma doença, formando agrupamentos criminais no espaço ao longo do tempo (DULCE; RAMÍREZ-AMAYA; RIASCOS, 2018; MOHLER et al., 2011). Por fim, uma vez que um crime acontece em um determinado local, ele provavelmente voltará a ocorrer naquela mesma área (AGUIRRE; BADRAN; MUGGAH, 2019).

A autoridade da predição criminal depende, assim, de uma rede densa de processos, que variam desde testes de validação baseados em análises estatísticas complexas e práticas de 'limpeza' dos dados, até métodos e categorizações desenvolvidos a partir de estudos quantitativos e análises baseadas na teoria do agente racional sobre o crime. Em seu cerne, também depende da composição e análise de riscos associados ao comportamento individual, às características do espaço e a elementos tão diversos quanto dia da semana e horário do dia, mediante técnicas como o modelo de risco de terreno (RTM, em inglês) e modelos baseados no agente (ABM, em inglês), entre outros.

O resultado dessa composição de riscos sobre como o crime (provavelmente) irá ocorrer e como criminosos (provavelmente) vão se comportar se materializa para o agente policial a partir de uma série de representações - em sua maioria geométricas - sobre um mapa do local.

Figura 1: Exemplo de mapa de mancha de calor criminal ${ }^{6}$

\footnotetext{
${ }^{6}$ O mapa representa o risco de ocorrências criminais em Santiago, Chile. Quanto mais forte a tonalidade de vermelho, maior o risco de se ter eventos. Pontos em amarelo indicam a real ocorrência criminal. Mapas de manchas de calor tendem a servir de base para predições criminais.
} 


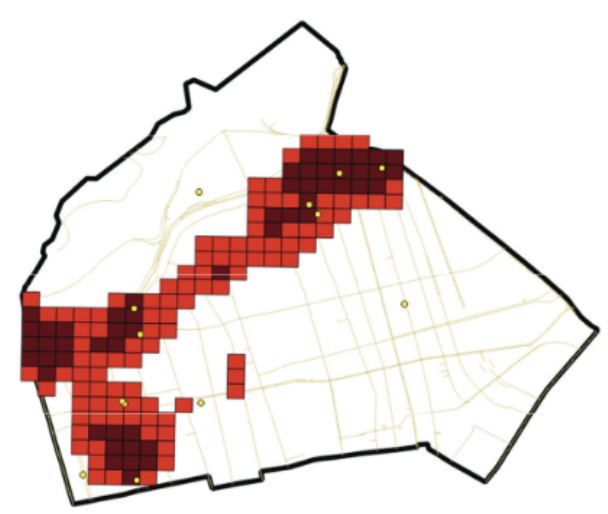

Fonte: Baloian et al. (2017)

Essas representações geométricas, em geral pontos, círculos, quadrados, hexágonos ou manchas com forma indistinta, indicam a concentração prevista de eventos resultante do processamento algorítmico sobre os elementos acima mencionados. Em alguns casos, utiliza-se determinada gradação de cores ou variações de intensidade de uma cor para sinalizar a maior ou menor probabilidade de um evento em um dado local. O principal dado é o dado histórico, que irá afetar diretamente o resultado da predição: uma quantidade pequena de dados disponíveis resulta em poucas ou nenhuma predição, ausência representada por grandes "vazios" no mapa. Já um n-grande é pressuposto para uma boa predição de crimes. A produção da predição depende da conjunção entre métodos estatísticos com uma série de fatores de risco.

Esse processo é similar ao que Hacking (1990) denomina "probabilidade da probabilidade", ou a probabilidade subjetiva de uma probabilidade objetiva. O caráter objetivo de uma probabilidade está diretamente associado a dois pressupostos: primeiro, que aquilo que se quer modelar constitui um fato objetivo. Por exemplo, o fato de que o comportamento criminal observa um cálculo de custo-benefício. Segundo, que este fato ocorre com certa frequência. Assim, por exemplo, na ausência de mecanismos de dissuasão, um mesmo tipo de crime - vamos dizer, roubo - tende a ocorrer repetidas vezes em um local. Em contrapartida, a probabilidade subjetiva está relacionada a uma convicção: a partir de inferências, alcançamos conclusões das quais não estamos absolutamente certos (por exemplo, qual a probabilidade de a predição do sistema estar correta?). É aqui que se torna possível falar do nível de confiança de uma estimativa. 
Modelagens e inferências conferem autoridade à predição de crimes. Aceitamos que a predição não corresponde cem por cento ao estado futuro dos eventos, porém confiamos que irá nos dizer, com a maior acurácia possível, onde é possível/necessário agir. Essa confiança é sobretudo reforçada pelas cartografias que compõem o fenômeno preditivo. A conjunção entre softwares de mapeamento, algoritmos preditivos e big data ajuda a legitimar a decisão de onde/como alocar o patrulhamento, atribuindo-lhe certa objetividade - em contraste com decisão similar empreendida sem recurso ao sistema. A justificativa sobre a alocação do recurso policial se desloca da 'subjetividade' policial para a do sistema, que 'sugere' que a alocação de efetivo pode ser feita segundo predições sobre ocorrências criminais. Isso ocorre porque há um grau maior de confiança na 'subjetividade' do sistema do que na subjetividade humana (e de atratividade pelo mapa na tela).

Essa confiança se baseia em uma combinação bastante específica entre correlação e causalidade: enquanto o sistema utiliza cálculos complexos para indicar uma correlação entre fatores que podem conduzir à manutenção ou aumento da atividade criminal em um dado espaço, a presença policial é compreendida como a principal causa responsável por dissuadir (e, com isso, modificar) padrões de comportamento criminal nesse espaço e, portanto, o uso do recurso policial para alocação de efetivo deve ocorrer de forma eficiente.

Por outro lado, no âmbito dos estudos de paz e conflito, projetos como o Correlates of War (SINGER; SMALL, 1972) buscam identificar eventos e variáveis que permitam prever a eclosão de crises e conflitos armados. Em particular, a crescente disponibilidade de dados relacionados a tais eventos - por exemplo, notícias de agências locais e internacionais e informações de redes sociais $-\mathrm{e} o$ desenvolvimento de capacidades para o seu processamento têm favorecido a criação de sistemas de alerta prévio voltados para a predição de conflitos e crises (HEGRE et al., 2017; ver também GURR; LICHBACH, 1986; BUENO DE MESQUITA, 2011).

Contudo, diferentemente do que ocorre com o policiamento preditivo, o campo da prevenção de crises e conflitos é marcado por uma predominância de esforços explicativos, ao invés da predição baseada na análise estatística de eventos agregados. Enfatiza-se a busca por inferências causais acerca de fenômenos como o 
início e o fim de guerras civis e interestatais, considerando-se variáveis como gastos militares, alianças ou padrões comerciais. Isso fica especialmente claro quando olhamos para os estudos de paz e transformação de conflitos e suas prescrições para a promoção da paz, cuja ênfase é a identificação e transformação de fatores "estruturais" ou "causas-raiz" da violência (ver GALTUNG, 1996; LEDERACH, 1997).

Tomemos como exemplo o caso do México, onde confrontos violentos entre grupos criminosos e entre estes e forças policiais são monitorados pelo International Crisis Group. O contexto no país é apresentado como uma "crise internacional" a partir do Crisis Watch, uma ferramenta de rastreamento de conflitos desenvolvida pela organização.

Figura 2: Mapa interativo do Crisis Watch $^{7}$ (Abril de 2020).

${ }^{7}$ O Crisis Watch é uma ferramenta desenvolvida pelo ICG para monitorar situações de crises e conflitos internacionais. Atualizado mensalmente, se propõe a oferecer a tomadores de decisão internacionais informações sobre tendências, risco de escalada e oportunidades de promoção da paz a respeito de mais de 80 conflitos e crises ao redor do mundo. 


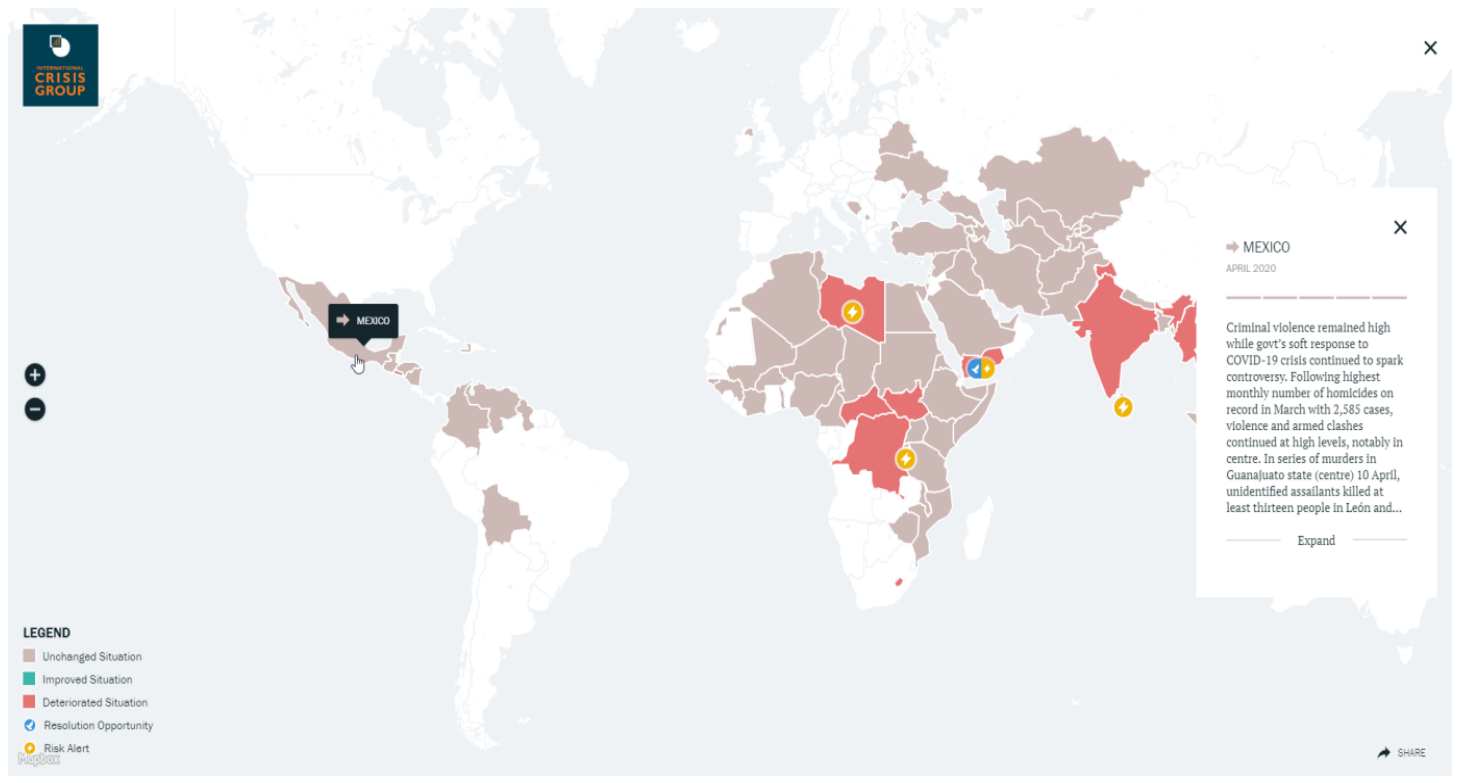

Fonte: International Crisis Group, 2020.

Esse rastreador global é apresentado na forma de um mapa interativo no qual é possível selecionar uma das "crises" monitoradas e ler sobre seus desenvolvimentos recentes. Os países monitorados são codificados na ferramenta em três cores: a situação não se modificou nos países marcados em marrom, melhorou nos marcados em verde, e se deteriorou nos países marcados em vermelho. Um ícone amarelo com um raio identifica ainda os "alertas de risco", enquanto um ícone azul com uma pomba identifica as "oportunidades de resolução". Os países que não são objeto do monitoramento da organização, por sua vez, são discretamente representados em branco.

Uma análise dos perfis dos países comumente marcados com o ícone amarelo dos "alertas de crise" revela os tipos de eventos que são tornados legíveis pela ferramenta. Estes incluem a erupção de confrontos violentos, protestos relacionados a eleições e ataques transfronteiriços, entre outros eventos lidos como "políticos" por sua conexão a disputas por governo ou controle territorial.

Os confrontos, no caso mexicano, são relatados em termos análogos aos utilizados para a descrição de conflitos armados, indicando um esforço para tornar o contexto mexicano legível nos termos estritos da expertise em crises internacionais e as prescrições associadas. Eventos como homicídios são representados não como 
pontos que se agregam em manchas de calor, mas sim como partes de uma ampla tendência que determina a cor atribuída ao país como um todo no mapa interativo.

O uso do Crisis Watch por funcionários de governos, organizações multilaterais, ONGs, setor privado, jornalistas e acadêmicos (ICG, s.d.d), além dos relatórios enviados ou entregues diretamente a "tomadores de decisão" e as newsletters de atualização enviadas por e-mail a milhares de assinantes (BLIESEMANN DE GUEVARA, 2014, p. 547) integram efetivamente essa rede de atores a uma comunidade de monitores internacionais que acompanham a evolução dos eventos representados pelo ICG como fontes de risco.

O modo como essa cartografia é construída perpassa a chamada "virada local" nas práticas voltadas para a construção da paz em meio a crises ou conflitos internacionais. Em certas perspectivas, essa valorização do "local" - construído em oposição ao "internacional" - representa uma crítica à imposição de modelos de governança eurocêntricos que desconsideram as concepções de paz dos atores locais. Em um entendimento mais comum, porém, enfatiza-se a necessidade de incluir as experiências locais na própria produção de conhecimento, em detrimento do privilégio do expert externo informado por generalizações acerca de crises e conflitos armados internacionais (PAFFENHOLZ, 2015; JULIAN; BLIESEMANN DE GUEVARA; REDHEAD, 2019).

Em conexão com este entendimento mais amplo da importância do conhecimento "local", o International Crisis Group deriva sua autoridade enquanto experts em crises e conflitos a partir da conjugação de seu status "internacional" e de sua extensa presença no "campo", que Ihes permitiria acessar mais diretamente as perspectivas locais. Esta última característica é mobilizada como fonte de distinção entre o ICG e os "think-tanks de poltrona" baseados em capitais ocidentais (BLIESEMANN DE GUEVARA, 2014).

O relato de um analista do ICG que conta sobre como suas interações com um sicário mexicano - "Nos encontramos quatro vezes. Fumamos juntos. Caminhamos até onde ele havia matado" (ICG, 2018), - ilustra a forma como o grupo articula sua presença em áreas do mundo em "crise" e suas redes de contato entre as "populações locais" como uma fonte de autoridade para o conhecimento produzido sobre tais 
zonas. Já os resultados do trabalho desses analistas alocados em "zonas de guerra e regiões remotas em crise" são incorporados a relatórios e listas de crises internacionais a serem monitoradas e geridas por "tomadores de decisão" internacionais. Assim, tais instrumentos são parte integral da composição de uma cartografia do risco global, que torna o "campo" legível na forma de crises espacialmente distribuídas pelo mundo. De acordo com o ICG,

\begin{abstract}
Nossa credibilidade e impacto estão fundados em pesquisa de campo, a qual é um processo interativo. Nossos analistas viajam a zonas de guerra e regiões remotas em crise, onde se encontram com um espectro especialmente amplo de pessoas, de oficiais de alto nível à mídia, e de ativistas da sociedade civil a comandantes de primeira linha. Nossos colegas não apenas fazem perguntas, eles compartilham informações, testam ideias e defendem recomendações que podem prevenir a eclosão de guerras e avançar a causa da paz (ICG, s.d.c).
\end{abstract}

O esforço para tornar a situação no México legível enquanto crise internacional, a ser gerida pelos mesmos mecanismos de governança que outros situações de "crise" ou "conflito armado", fica explícito em outros relatórios produzidos pelo ICG. Por exemplo, em uma das watch lists divulgadas em 2019, a "epidemia de violência" no México foi incluída como um dos principais contextos para os quais os tomadores de decisão da União Europeia (UE) deveriam voltar sua atenção. Sugeriu-se, inclusive, que a UE e seus estados membros recomendassem ao governo mexicano enquadrar sua 'guerra às drogas' como um conjunto de conflitos armados internos, o que permitiria uma mudança para políticas de segurança ajustadas regionalmente, incluindo práticas de peace building como a desmobilização de jovens combatentes nas regiões do país com maior enfrentamento (ICG, 2019a). Essa proposta reflete reivindicações de determinadas organizações da sociedade civil mexicana (CMDPDH, 2019), embora esteja longe de ser consensual, devido ao risco da legitimação de respostas estatais militarizadas. Por outro lado, esse enquadramento possibilita formas de intervenção internacional associadas ao campo da governança global, como será explorado na próxima seção.

Crucialmente, o conhecimento produzido sobre um contexto de violência ligada ao crime organizado e ao seu combate por vias militarizadas torna o problema do "crime" legível de forma distinta daquela observada no contexto do policiamento 
preditivo. Se naquele contexto, o crime é lido como um agregado de comportamentos individuais tipificados legalmente, que pode ser representado em um mapa de manchas de calor a partir de recursos estatísticos, aqui o crime aparece na forma de uma crise internacional, acessada por experts internacionais alocados no campo. Se no contexto do policiamento preditivo a expertise estatística é mobilizada como fonte de autoridade das informações que desloca o problema da "subjetividade", no contexto da gestão de crises internacionais a "expertise do campo" (BLIESEMANN DE GUEVARA, 2014) é articulada de maneira a autorizar o conhecimento produzido pelo ICG, que seria produzido a partir de interações com os mais diversos atores "locais". A partir dessas duas formas de tornar o "crime" legível, formas de intervenção distintas são autorizadas, como será discutido na próxima seção.

\section{Cartografias, intervenções e a construção da autoridade da prevenção do "crime"}

Retomemos a observação de Freeman (1999), segundo a qual a prevenção pode ser entendida como uma composição das capacidades de predizer e intervir. Idealizada a partir do policiamento preditivo, que se baseia fortemente na premissa de que a prática de crimes pode ser "antecipada", a prevenção implica formas de intervenção distintas daquelas encontradas na prevenção de crises e conflitos e sua ênfase na identificação de mecanismos causais. Mecanismos explicativos, como "o aumento da criminalidade em uma região $X$ se deve à presença do crime organizado na área", têm importância limitada para um sistema cujo intuito é indicar apenas a probabilidade de haver eventos criminais nessa região para informar a alocação de efetivos policiais. No caso de crises internacionais, por outro lado, a quantificação da probabilidade de uma crise em determinada parte do globo diria pouco sobre o tipo de transformação política a ser prescrita por especialistas internacionais de forma a prevenir sua eclosão.

Dessa forma, os modelos de prevenção do "crime" contemplados por sistemas de alerta prévio e pelo policiamento preditivo ilustram a distinção entre "soluções" que intervêm sobre padrões de comportamento e aquelas que agem sobre suas causas. 
Por exemplo, a lógica de prevenção do crime que prevalece na maioria dos sistemas de policiamento preditivo (FLORES ARIAS, 2014; ANGWIN et al. 2016; DULCE; RAMÍREZ-AMAYA; RIASCOS, 2018; KAUFMANN; EGBERT; LEESE, 2018; AGUIRRE; BADRAN; MUGGAH, 2019) é uma segundo a qual se oferece uma resposta 'espacial' a um problema que também se manifesta no espaço: o ato criminal. Não se busca combater necessariamente as causas do crime, mas dissuadir o comportamento criminal: importa assegurar que o evento criminal não aconteça mediante a (re)alocação de recursos policiais, como patrulhar uma determinada rua ou alocar uma viatura para uma esquina sabidamente 'problemática'.

Assim, no policiamento preditivo, uma análise das "causas" do crime é deixada em segundo plano exatamente porque se pressupõe que a presença policial dissuade um determinado conjunto de comportamentos. Em outras palavras, o patrulhamento - entendido como a presença visível de um policial na comunidade, a pé ou em veículos identificados (TELEP et al., 2016) - é naturalizado enquanto solução, e o único problema está em saber como alocá-lo em diferentes áreas da cidade de forma mais "eficiente". A visibilidade do policial é entendida como particularmente crucial nesta forma de intervenção, funcionando tanto para dissuadir potenciais "criminosos" quanto para fomentar uma percepção de segurança junto à comunidade. Desse modo, disputas neste campo de práticas tendem a se limitar ao campo de como melhor gerenciar a presença policial, girando em torno de questões como qual seria a melhor distribuição dos efetivos entre os "hot spots" e outras áreas para evitar o "deslocamento" do crime para o restante da cidade (ver JOHNSON; GUERETTE; BOWERS, 2014; BRAGA; PAPACHRISTOS; HUREAU, 2012).

Por outro lado, a priorização da presença policial enquanto forma de intervenção preventiva torna ilegíveis uma série de outros comportamentos igualmente tipificados como "crimes", sendo o mais evidente as próprias violações cometidas por agentes policiais. Afinal, em áreas urbanas nas quais a presença policial está longe de contribuir para um aumento da "percepção de segurança", quaisquer "soluções" para a insegurança precisariam ser concebidas em outros termos. Iniciativas como o "Mapping Police Violence", que reproduz cartograficamente homicídios perpetrados 
por policiais nos Estados Unidos, ${ }^{8}$ permitem uma reflexão sobre os limites da concepção do "crime" enquanto problema a ser prevenido através da realocação de efetivos policiais, na medida em que a presença destes e a ausência de serviços básicos podem também ser fatores de insegurança.

Da mesma forma, o fato de que crimes como aqueles de "colarinho branco" não se prestam às mesmas práticas de legibilidade e intervenção ilustra os limites de uma lógica de prevenção pautada pela identificação de certas comunidades como espaços de "risco", o qual pode ser gerenciado através da presença do Estado - em sua forma policial. Em outras palavras, assim como a legibilidade do "crime" em termos de manchas de calor que podem ser mapeadas em espaços urbanos autoriza a redistribuição do patrulhamento como intervenção preventiva, o contrário também se verifica: o policiamento preditivo torna possível a legibilidade de certas práticas enquanto parte do "problema" do crime, enquanto invisibiliza outras.

Nesse sentido, a cartografia das predições criminais opera de maneira perlocucionária: ela persuade e convence, comunicando a eventual consequência da inação (a intensificação da mancha criminal). Ela deriva seu poder de um conjunto de métodos, modelos, processos de validação e especialistas, que trabalham para traduzir um assalto - ou talvez, um homicídio - em um evento em um mapa. Claro, é uma cartografia que também oculta. Oculta os crimes que atualmente não são tão facilmente passíveis de serem computados espacialmente, como a violência de gênero, e também oculta a violência geradora do próprio crime violento: desigualdades, exclusão social e, claro, racismo. Essa cartografia incorpora um julgamento silencioso, favorecendo crimes violentos, ignorando tipos de crimes financeiros "de colarinho branco", além de validar práticas policiais sabidamente discriminatórias (GONZÁLEZ; CORREA, 2019). Ela fornece contexto geográfico a incidentes criminais, enquanto faz pouco contra o contexto já incorporado na geografia (p.ex., segregação espacial e de classe). A legibilidade da desordem urbana, compreendida enquanto um conjunto de eventos que se desdobram no espaço, e as

\footnotetext{
8 "Mapping Police Violence is a research collaborative collecting comprehensive data on police killings nationwide to quantify the impact of police violence in communities." Disponivel em: https://mappingpoliceviolence.org/ Acesso em 23 Jan. 2020.
} 
formas de intervenção orientadas para a distribuição espacial da presença do estado, se reforçam mutuamente.

Já no contexto das práticas de "gestão de crises internacionais", outras formas de intervenção são tornadas possíveis em nome da prevenção de outra "Ruanda" ou "Srebrenica". No relatório publicado pela ICISS em 2001 que inaugura o conceito de responsabilidade de proteger, as intervenções preventivas recomendadas se dividem entre aquelas voltadas para as "causas-raiz", como programas de cooperação para o desenvolvimento, assistência técnica, apoio ao desenvolvimento de instituições democráticas e reformas do setor de segurança; e esforços de prevenção "direta", que incluem atividades de mediação ou mesmo a ameaça de sanções internacionais, buscando resultados no curto prazo (ICISS, 2001). Esse tipo de práticas aparece como prescrição também nos relatórios de organizações como o ICG, na forma de recomendações para os Estados alvo e para tomadores de decisão internacionais. Não por acaso, um dos coordenadores da ICISS à época, Gareth Evans, era também o presidente do ICG, além de ex-Primeiro-Ministro da Austrália - ilustrando o papel dos "estadistas" de alto nível na forma como o International Crisis Group se coloca como um ator influente no campo da gestão de crises internacionais.

Enquanto a emergência do conceito de R2P gerou reações críticas devido à legitimação da intervenção humanitária, a maioria dos atores internacionais estavam dispostos a apoiar o uso do conceito com referência a "formas mais suaves de ação internacional, como assistência humanitária, construção de capacidades, ajuda para o desenvolvimento e reformas" (ORFORD, 2011, p.27). Contudo, tais práticas podem ser lidas como parte da história da emergência de uma forma de autoridade internacional, consolidando a atribuição de um "papel policial e gerencial para a ONU" (ORFORD, 2011, p.189). Em outras palavras, o argumento pela priorização da prevenção torna mais aceitável a consolidação de práticas por meio das quais áreas do globo construídas como "problemáticas" podem ser diagnosticadas pelos "experts em crises" e gerenciadas por uma estrutura de atores internacionais, através de ferramentas que também são discutidas no campo da técnica - como reformas institucionais, construção de capacidades e programas de assistência. 
Na medida em que contextos de violência associada ao "crime organizado" e ao seu combate por agentes estatais passam a ser compreendidos como parte do rol de "crises internacionais", formas similares de intervenção passam a ser prescritas também para estes contextos. No caso das prescrições feitas pelo ICG com respeito ao contexto mexicano, a organização tem criticado as políticas de segurança sob a presidência de López Obrador: eleito após uma campanha em que criticava a estratégia militarista de "guerra às drogas" de governos anteriores, o presidente estabeleceu uma Guarda Nacional composta principalmente por militares como sua principal força de segurança, a despeito de alegar priorizar soluções socioeconômicas para a violência no país. Em oposição, o International Crisis Group recomenda que políticas socioeconômicas sejam conjugadas a práticas de segurança que protejam "populações civis" no curto prazo, somadas a medidas que promovam a responsabilização de agentes estatais por potenciais violações de direitos humanos e por casos de corrupção. Além disso, a organização propõe que "potências externas" ofereçam assistência técnica para reformas institucionais, especialmente para a "profissionalização" de forças policiais, bem como ajuda técnica e financeira para os mecanismos de buscas de desaparecidos no país (ICG, 2019b).

Como já mencionado, há importantes conexões entre os diagnósticos e recomendações oferecidos pelo ICG e aqueles de uma parcela importante dos especialistas e ativistas nacionais. Contudo, tais recomendações vindas de um conjunto de "experts em crises internacionais" deslocam o problema do "crime" no país da esfera das discussões sobre políticas públicas nacionais para aquela da "política internacional". Para tanto, informações obtidas através das interações entre o analista em campo e atores locais são condensadas na forma de diagnósticos e recomendações legíveis nos termos da prevenção de atrocidades e peace building. Estes efeitos da mediação feita pelo ICG entre o campo e os decisores internacionais ficam particularmente claros na inclusão do México como país monitorado pelo Crisis Watch e, por extensão, dos confrontos ligados ao "crime organizado" no país como um cenário de crise internacional que demanda intervenção externa.

Tais confrontos são agregados na forma de uma tendência nacional que permite reavaliar, mensalmente, o nível de atenção que deve ser reservado ao México pela 
comunidade internacional, bem como o nível de urgência das intervenções recomendadas. A complexidade apresentada em vários relatórios da organização (p.ex., quando se demanda a adoção de políticas de segurança adequadas a cada região) são aqui substituídas pela codificação em cores por país. Da mesma forma, as causas da violência e sua historicidade são substituídas pela visualização da cor atribuída ao México nos últimos seis meses. Assim, a cartografia do risco internacional, tornada explícita no mapa interativo do Crisis Watch, reorienta a atenção dos membros de uma "comunidade internacional" imaginada em torno da responsabilidade de agir na prevenção da violência; mas o faz através de simplificações que tornam possível a comparação e priorização entre contextos tão distintos, em detrimento das nuances que se busca obter com o envio de analistas para o "campo".

Desse modo, nota-se que enquanto a lógica preventiva expressa pelo policiamento preditivo torna o "crime" legível enquanto padrões espacializados de comportamento, que podem ser transformados através da realocação de efetivo policial, a lógica preventiva da gestão de crises internacionais torna o "crime" legível enquanto crise internacional a ser prevenida a partir da promoção de práticas de "boa governança" apoiadas por atores internacionais. Enquanto a primeira enfatiza a predição apoiada em uma expertise estatística sob o argumento de um deslocamento da "subjetividade" na alocação de efetivos policiais, a segunda lógica enfatiza a necessidade de agir sobre os fatores (ou causas) que alimentam uma crise, os quais são identificados a partir da pesquisa em campo.

A mobilização de conhecimentos estatísticos, no caso do policiamento preditivo, e do campo, no caso da gestão de crises internacionais, conferem autoridade a determinadas representações do fenômeno criminal. As cartografias que produzem invocam modos particulares de intervenção que operam com base na priorização de certas medidas, digamos uma maior presença policial ou a assistência técnica à profissionalização do setor de segurança, em detrimento de outras.

Tanto no caso de cartografias do risco expressas em mapas de manchas criminais quanto naquelas expressas em mapas interativos de crises internacionais, destaca-se a representação espacial de eventos recentes. Enquanto no primeiro caso 
estes eventos são agregados estatisticamente, no segundo, se manifestam na forma de uma única tendência nacional (uma situação que melhorou, piorou ou se manteve igual). No caso do policiamento preditivo, a representação dos crimes como eventos espacialmente demarcados é central para a intervenção proposta - a realocação do patrulhamento, que dispensa uma análise das causas do crime.

Já no caso da gestão de crises internacionais, a representação de confrontos violentos recentes como tendências nacionais que permitem a classificação dos Estados busca equiparar contextos distintos e reorientar as prioridades e sentimentos de urgência na "comunidade internacional". Contudo, ao privilegiar a representação da distribuição destes confrontos recentes no espaço, um mapa de crises internacionais relega ao segundo plano tanto a evolução histórica das crises monitoradas quanto às causas-raiz que as intervenções usualmente prescritas, como a promoção da "boa governança", buscam transformar.

A possibilidade oferecida por contra-cartografias e/ou cartografias insurgentes ${ }^{9}$ ilustra o modo como o enquadramento do crime, e os modos de intervenção autorizados a partir disso, são contingentes também às técnicas e instrumentos mobilizados para tornar legíveis apenas certos aspectos seus. Outras cartografias da insegurança e da violência evidenciam isto ao tornar legíveis, por exemplo, práticas violentas incompatíveis com formas de intervenção hegemônica, como em mapas da violência policial e dos feminicídios; ${ }^{10}$ ou por deslocar a centralidade da espacialidade de eventos em favor das causas da violência e de sua historicidade, ${ }^{11}$ ou de seus impactos sobre os corpos das vítimas. ${ }^{12}$ Além disso, sistemas de alerta prévio baseados nas próprias comunidades podem rearticular a prevenção da violência

9 Ver as cartografias produzidas sobre as comunidades em favelas no Rio de Janeiro. Disponíveis nos links http://www.canalibase.org.br/cartografia-insurgente-quem-constroi-nossos-mapas-somos-nos/ e https://fase.org.br/wp-content/uploads/2015/05/Jornal Cartografia Mare Maio2015.pdf.

10 Ver mapa de feminicídios no México, projeto de María Salguero. Disponível em: https://verne.elpais.com/verne/2017/04/20/mexico/1492712075 304797.html.

11 Para contra-cartografias produzidas por povos indígenas e movimentos sociais, ver https://www.countercartographies.org/wp-content/files/Mason-

DeeseCounterMappingEncylEntryFinal.pdf

12 A cartografia corporal toma como ponto de partida a representação visual do próprio corpo como território no qual se podem visualizar os impactos da vida de uma comunidade. Ver: https://miradascriticasdelterritoriodesdeelfeminismo.files.wordpress.com/2017/11/mapeando-elcuerpo-territorio.pdf 
através de processos mais participativos e inclusivos, incorporando indicadores que são específicos para um determinado contexto local em detrimento das lentes únicas do expert em crises internacionais (LEACH, 2016). Tais exemplos ilustram não apenas o modo como diferentes lógicas de intervenção se articulam na prática, como também as possibilidades de (re)configuração das relações que essas lógicas priorizam nas representações que produzem.

\section{Considerações finais}

Sistemas de policiamento preditivo e mecanismos de prevenção de crises internacionais participam de uma composição de formas de intervenção visando a produção de uma certa ordem. No primeiro caso, eventos como assaltos, furtos e homicídios, entre outros, são tornados legíveis na forma de manchas de calor criminais. À medida que são fixadas em um mapa, a espacialidade dessas condutas é destacada como o principal aspecto que deve informar uma intervenção preventiva - e a distribuição espacial da patrulha policial é adaptada para corresponder a essa espacialidade. No segundo contexto, a produção da ordem é concebida principalmente em termos da reprodução de determinados modelos de "boa governança", prescritos por atores reconhecidos como "experts" em crises internacionais e apoiados por "tomadores de decisão" de esferas de governança global. A autoridade dessas prescrições, por sua vez, é indissociável de uma cartografia do risco global produzida a partir da presença do analista de crises no "campo", presença essa apresentada como evidência do acesso direto ou autêntico à realidade local.

Em ambos os contextos, a partir da articulação das expertises estatística ou baseada no "campo", diagnósticos específicos acerca do "crime" enquanto problema são legitimados, autorizando formas específicas de intervenção para a produção da ordem. Por sua vez, a configuração do problema criminal enquanto risco evoca a necessidade de atuação no presente para evitar sua escalada ou atualização futura. Em ambos os casos, as formas de intervenção demandadas (presença policial ou reformas institucionais), se apresentam como tecnicamente superiores às 
alternativas, o que relega outras concepções de produção da ordem, por exemplo, que coloquem em questão o paradigma da presença policial ou a reprodução de determinados modelos do setor de segurança estatal, para além do limitado horizonte concebível em tais campos de práticas.

Nesse contexto o espaço para disputas políticas envolvendo diferentes concepções de "ordem" ou "paz" é minimizado em favor de discussões tecnicistas acerca de como a "desordem" pode ser mais eficientemente gerenciada. Ao mesmo tempo, uma ênfase no crime enquanto elemento comum a ambas as lógicas sugere um deslocamento da própria distinção entre o "local" e o "global" na figura do fenômeno criminal, articulado tanto enquanto evento espacial, no caso do policiamento preditivo, quanto crise internacional, no caso da gestão de crises internacionais. No entanto, a atenção sobre como diferentes lógicas da prevenção (predição, explicação) se traduzem em formas de intervenção específicas (patrulhamento, boa governança) no contexto de práticas de policiamento preditivo e da gestão de crises internacionais também nos recorda que há outros modos possíveis de se representar a insegurança e a violência para além do fenômeno criminal. Se, por um lado, essas lógicas limitam a concepção da ordem ao gerenciamento do risco, por outro lado, compreender que ao mesmo tempo são partes de articulações específicas de saberes (matemático-estatístico, do "campo") nos permite vislumbrar que essa mesma ordem que produzem pode ser contornada, subvertida e re-imaginada.

\section{Referências}

AGUIRRE, Kathe; BADRAN, Emile; MUGGAH, Robert. Future crime: Assessing twenty first century crime prediction. Rio de Janeiro: Instituto Igarapé, jul. 2019.

AMOORE, Louise. The politics of possibility: Risk and security beyond probability. Durham: Duke University Press, 2013.

ANGWIN, Julia; LARSON, Jeff; MATTU, Surya; KIRCHNER, Laura. Machine Bias: There's software used across the country to predict future criminals. And it's biased against blacks. ProPublica, 23 maio 2016. 
ARADAU, Claudia.; VAN MUNSTER, Rens. Governing Terrorism Through Risk: Taking Precautions, (un)Knowing the Future. European Journal of International Relations, 13(1), p. 89-115, 2007.

BALOIAN, Nelson; BASSALETTI, Col. Enrique; FERNÁNDEZ, Mario; FIGUEROA, Oscar; FUENTES, Pablo; MANASEVICH, Raúl; ORCHARD, Marcos; PEÑAFIEL, Sergio; PINO, José A.; VERGARA, Mario. [BALOIAN et al.], "Crime Prediction Using Patterns and Context." Proceedings of the 2017 IEEE 21st International Conference on Computer Supported Cooperative Work in Design (CSCWD), 2017, p.2-9. Disponível em: http://ieeexplore.ieee.org/document/8066662/. Acessado em 05 de julho de 2019.

BATITUCCI, Eduardo Cerqueira. Gerencialismo, estamentalização e busca por legitimidade: O campo policial militar no Brasil. Revista Brasileira de Ciências Sociais, v. 34, 2019.

BEVIR, Mark. Key Concepts in Governance. [s.I.] SAGE Publications, 2009.

BLIESEMANN DE GUEVARA, Berit. On methodology and myths: exploring the International Crisis Group's organisational culture. Third World Quarterly, v. 35, n. 4, p. 616-633, 2014.

BRAGA, Anthony. A., PAPACHRISTOS, Andrew. V., \& HUREAU, David M. The Effects of Hot Spots Policing on Crime: An Updated Systematic Review and MetaAnalysis. Justice Quarterly, v. 31, n. 4, p. 633-663, 2012.

BUENO DE MESQUITA, Bruce. A new model for predicting policy choices and preliminary tests. Conflict Management and Peace Science, v. 28, n. 1, p. 65-87, 2011.

CALLON, Michel; MUNIESA, Fabian. Peripheral Vision: Economic Markets as Calculative Collective Devices. Organization Studies, 26(8), p. 1229-1250, 2005.

Center for analysis and modelling of security [CEAMOS]. [s.d.]. Disponível em: $<$ http://ceamos.cl/>. Acessado em 30 de junho de 2019

CHADEFAUX, Thomas. Conflict forecasting and its limits. Data Science, v. 1, p. 717, 2017.

COMISIÓN MEXICANA DE DEFENSA Y PROMOCIÓN DE LOS DERECHOS HUMANOS [CMDPDH], La situación de la violencia relacionada con las drogas en México del 2006 al 2017: ¿es un conflicto armado no internacional? México: Comisión Mexicana de Defensa y Promoción de los Derechos Humanos, 2019.

DEVIA, Nelson; WEBER, Richard. Generating crime data using agent-based simulation. Computers, Environment and Urban Systems, v. 42, p. 26-41, 2013. 
DULCE, Mateo; RAMíREZ-AMAYA, Simón; RIASCOS, Álvaro. Efficient allocation of law enforcement resources using predictive police patrolling. Disponível em: <https://arxiv.org/abs/1811.12880>. Acessado em 30 de novembro de 2018.

FLORES ARIAS, Paulina V. Modelación y predicción de focos de criminalidad basado en modelos probabilísticos. Santiago, Chile: Universidad de Chile, Facultad de Ciencias Físicas y Matemáticas, 2014.

FREEMAN, Richard. Recursive Politics: Prevention, modernity and social systems. Children \& Society, v. 13, p. 232-241, 1999.

GALTUNG, Johan. Peace by peaceful means: peace and conflict, development and civilization. Londres: SAGE Publications, 1996.

GILLING, Daniel. Crime prevention: theory, policy and politics. Londres: Routledge, 1997.

GONZÁLEZ, María de Arteaga; CORREA, Mária Cúellar. Algoritmos y crímenes, Semana, 4 de abril de 2019. Disponível em: $<$ https://www.semana.com/opinion/articulo/prevencion-de-delitos--columnistas-mariade-arteaga-gonzalez-y-maria-cuellar-correa/608182>. Acessado em 11 de janeiro de 2020.

GUNDHUS, H. O. 'Catching' and 'Targeting': Risk-Based Policing, Local Culture and Gendered Practices. Journal of Scandinavian Studies in Criminology \& Crime Prevention, v. 6, n. 2, p. 128-128, 2005.

GURR, Ted Robert; LICHBACH, Mark Irving. Forecasting internal conflict: A competitive evaluation of empirical theories. Comparative Political Studies, v. 19, n. 1, p. 3-38, 1986.

HACKING, lan. The Taming of Chance. Cambridge: Cambridge University Press, 1990.

HEGRE, Håvard; METTERNICH, Nils W.; NYGARD, Håvard Mokleiv; WUCHERPFENNIG, Julian. [HEGRE et al.] Introduction: Forecasting in peace research, Journal of Peace Research, p. 1-12, 2017.

HOCHMÜLLER, Markus; MÜLLER, Markus-Michael. Encountering knowledge production: the International Crisis Group and the making of Mexico's security crisis. Third World Quarterly, v. 35, n. 4, p. 705-722, 2014.

INSTITUTE FOR ECONOMICS \& PEACE. Global Terrorism Index 2018: Measuring the impact of terrorism, Sydney, Novembro de 2018. Disponível em: <http://visionofhumanity.org/app/uploads/2018/12/Global-Terrorism-Index-20181.pdf> Acessado em 24 de Janeiro de 2020. 
INTERNATIONAL COMMISSION ON INTERVENTION AND STATE SOVEREIGNTY [ICISS]. The Responsibility to Protect: Report of the International Commission on Intervention and State Sovereignty. Ottawa: International Development Research Centre, 2001.

INTERNATIONAL CRISIS GROUP [ICG]. Who we are. Preventing War. Shaping Peace. [s.d. a]. Disponível em: <https://www.crisisgroup.org/who-we-are> Acessado em 24 de setembro de 2019.

INTERNATIONAL CRISIS GROUP [ICG]. Who we are. History. [s.d. b]. Disponível em: $<$ https://www.crisisgroup.org/who-we-are/history> Acessado em 24 de setembro de 2019.

INTERNATIONAL CRISIS GROUP [ICG]. Our Journeys. [s.d. c]. Disponível em: $<$ https://www.crisisgroup.org/how-we-work/our-journeys> Acessado em 20 de janeiro de 2020.

INTERNATIONAL CRISIS GROUP [ICG]. About CrisisWatch. [s.d. d]. Disponível em: $<$ https://www.crisisgroup.org/how-we-work/our-journeys> Acessado em 24 de maio de 2020 .

INTERNATIONAL CRISIS GROUP [ICG]. The Life and Death of a Mexican Hitman. 2018. Disponível em: <https://www.crisisgroup.org/how-we-work/our-journeys> Acessado em 20 de janeiro de 2020.

INTERNATIONAL CRISIS GROUP [ICG]. Watch List 2019 - First Update. 17 de abril de 2019 [2019a]. Disponível em <https://www.crisisgroup.org/how-we-work/ourjourneys> Acessado em 20 de janeiro de 2020.

INTERNATIONAL CRISIS GROUP [ICG]. Picking Up the Pieces after Mexico's Criminal Siege. 22 de outubro de 2019 [2019b] Disponível em: $<$ https://www.crisisgroup.org/latin-america-caribbean/mexico/picking-pieces-aftermexicos-criminal-siege> Acessado em 20 de janeiro de 2020.

INTERNATIONAL CRISIS GROUP [ICG]. CrisisWatch. Global Overview - April 2020 [2020]. Disponível em: <https://www.crisisgroup.org/crisiswatch> Acessado em 24 de maio de 2020.

JOHNSON, Shane D., GUERETTE, Rob T. \& BOWERS, Kate. Crime displacement: what we know, what we don't know, and what it means for crime reduction. $J$ Exp Criminol v. 10, p. 549-571, 2014.

JONES, Trevor; NEWBURN, Tim. THE TRANSFORMATION OF POLICING? Understanding Current Trends in Policing Systems. The British Journal of Criminology, v. 42, n. 1, p. 129-146, 2002. 
JULIAN, Rachel; BLIESEMANN DE GUEVARA, Berit; REDHEAD, Robin. From expert to experiential knowledge: exploring the inclusion of local experiences in understanding violence in conflict, Peacebuilding, v. 7, n. 2, p. 210-225, 2019.

KAUFMANN, Mareile; EGBERT, Simon; LEESE, Matthias. Predictive Policing and the Politics of Patterns. The British Journal of Criminology, v. 59, n. 3, p. 674-692, 2018.

KITCHIN, Rob. Big Data, new epistemologies and paradigm shifts. Big Data \& Society, v. 1, n. 1, 2014.

LAB, Steven P. Crime prevention, 7 ed. New Providence: LexisNexis, 2010.

LEACH, Steven. "Preventing Violence: Community-based Approaches to Early Warning and Early Response", CSS Mediation Resources. Zurique: Center for Security Studies (CSS), 2016.

LEDERACH, John Paul. Building peace: sustainable reconciliation in divided societies. Washington: United States Institute of Peace, 1997.

MAGUIRE, Mike; MCVIE, Susan. 7. Crime data and criminal statistics: a critical reflection. In: MAGUIRE, Mike; MCVIE, Susan (Eds.). The Oxford Handbook of Criminology. [s.I.] Oxford University Press, 2017.

MCALLISTER, James; LABROSSE, Diane (EDS.). What We Talk About When We Talk About Nuclear Weapons. In: H-DIPLO | ISSF FORUM, No. 2. 15 de junho de 2014. Disponível em: <http://issforum.org/ISSF/PDF/ISSF-Forum-2.pdf>. Acesso em: 11 de janeiro de 2020.

MEARSHEIMER, John J.; WALT, Stephen M. Leaving theory behind: Why simplistic hypothesis testing is bad for International Relations. European Journal of International Relations, v. 19, n. 3, p. 427-457, 2013.

MOHLER, George; SHORT, M.; BRANTINGHAM, P.; SCHOENBERG, F.; TITA, George [MOHLER et al.]. Self-Exciting Point Process Modeling of Crime. Journal of the American Statistical Association, v. 106, n. 493, p. 100-108, 2011.

MUGGAH, Robert. Does Predictive Policing Work?The Cipher Brief, 4 dez. 2016. Disponível em: <https://www.thecipherbrief.com/does-predictive-policing-work>. Acessado em 27 de fevereiro de 2018

NYHEIM, David. Preventing violence, war and state collapse: The future of conflict early warning and response. Paris: Organization of Economic Cooperation and Development, 2009.

O'MALLEY, Pat; HUTCHINSON, Steven. Converging Corporatization? Police Management, Police Unionism, and the Transfer of Business Principles. Police Practice \& Research, v. 8, n. 2, p. 159-174, 2007. 
ORFORD, Anne. International authority and the responsibility to protect. Cambridge: Cambridge University Press, 2011.

PAFFENHOLZ, Thania. Unpacking the local turn in peacebuilding: a critical assessment towards an agenda for future research. Third World Quarterly, v. 36, n. 5, p. 857-874, 2015.

RESCHER, Nicholas. On prediction and explanation. The British Journal for the Philosophy of Science, v. VIII, n. 32, p. 281-290, 1958.

SINGER, Joel David; SMALL, Melvin. The wages of war, 1816-1965: a statistical handbook. Wiley, 1972.

SPRINZ, Detlef F.; WOLINSKY-NAHMIAS, Yael (eds.). Models, numbers, and cases: methods for studying international relations. Ann Arbor: University of Michigan Press, 2004.

TELEP, Cody W.; WEISBURD, David; WIRE, Sean; FARRINGTON, David [TELEP et al.]. PROTOCOL: Increased Police Patrol Presence Effects on Crime and Disorder. Campbell Systematic Reviews, v. 12, p. 1-35, 2016.

TERPSTRA, Jan; TROMMEL, Willem. Police, managerialization and presentational strategies. Policing: An International Journal of Police Strategies \& Management, v. 32, n. 1, p. 128-143, 2009.

WAKEFIELD, Alison; FLEMING, Janny (Eds.) The SAGE Dictionary of Policing, p. 196-198. London: SAGE, 2020.

WHITE, Adam; GILL, Martin. The Transformation of Policing: From Ratios to Rationalities. The British Journal of Criminology, v. 53, n. 1, p. 74-93, 2012.

ZENKO, Micah; FRIEDMAN, Rebecca R. UN Early Warning for Preventing Conflict, International Peacekeeping, v. 18, n. 1, p. 21-37, 2011.

Recebido em: 24/01/2020

Aprovado em: 06/09/2020 